\title{
HUBUNGAN ANTARA INTENSITAS PEMERIKSAAN KEHAMILAN, FASILITAS PELAYANAN KESEHATAN DAN KONSUMSI TABLET BESI DENGAN TINGKAT KELUHAN SELAMA KEHAMILAN
}

\author{
(Correlations between Intensity of Pregnancy Inspection, Facility of Health Service and \\ Iron Tablet with Mount the Sigh Experienced during Pregnancy)
}

\author{
Marissa Indreswari ${ }^{1}$, Hardinsyah ${ }^{2}$, dan M. Rizal Martua Damanik ${ }^{2}$
}

\footnotetext{
${ }^{1}$ Alumnus Program Studi Gizi Masyarakat dan Sumberdaya Keluarga, Fakultas Pertanian (FAPERTA) IPB.

2 Staf Pengajar Departemen Gizi Masyarakat, Fakultas Ekologi Manusia (FEMA), IPB Telp: 0251-8628304/8621258; Fax: 0251-8625846/8622276.
}

\begin{abstract}
Pregnant mother is one of the group gristle nutrition. Pregnant mother need to do medical check during pregnancy to support quality of good health. Pregnancy inspection is suggested minimum four times during pregnancy. The aim of this study is to analyze correlation between intensity of pregnancy inspection, facility of health service and the iron tablet consumption with mount the sigh experienced during pregnancy. This study used the cross sectional study method with sample taking method by purposive in Kramat J ati Sub-district (East J akarta) and Ragunan Sub-district (South J akarta). Total sample taken for this study were 100 pregnant mothers (50 from each regional). Data obtained was processed by Microsoft Excel 2003 and analyzed by SPSS 13.0 for windows. Analyze data used Rank Correlation Spearman to know the correlation between variables. Results showed significant correlations between iron tablet consumption obedience with intensity of pregnancy inspection. Significant correlation was also shown by intensity of pregnancy inspection variable with facility of health service which got by pregnant mother during pregnancy inspection. This result study was strenghtened by previous study that showed intensity of pregnancy inspection to the health service had strong correlation with antenatal care which obtained by pregnant mother.
\end{abstract}

Keywords: pregnancy inspection, facility of health service, iron tablet consumption

\section{PENDAHULUAN}

\section{Latar Belakang}

Kondisi terpenuhinya kebutuhan zat gizi pada seorang anak bukan hanya bergantung pada asupan makanannya saat ini namun juga terkait dengan status gizi pada masa lalu bahkan sejak ia masih berada dalam rahim seorang ibu. Status gizi janin yang masih berada dalam kandungan bergantung pada status gizi ibu. Hal ini dikarenakan asupan makanan janin hanya dapat melalui tali pusat yang terhubung kepada tubuh ibu. Oleh karena itu, wanita yang sedang mengandung hendaknya lebih memperhatikan asupan gizi dari makanan agar tumbuh kembang janin berlangsung optimal.

Ibu hamil merupakan salah satu kelompok yang rawan akan masalah-masalah gizi. Ibu hamil yang diindikasikan menderita anemia yaitu sejumlah $40.1 \%$ dari jumlah total wanita usia subur (WUS) di Indonesia (Depkes RI, 2003). Prevalensi anemia, angka kematian ibu (AKI), angka kematian bayi (AKB), dan berat badan bayi lahir rendah (BBLR) dapat memperlihatkan adanya indikasi kerawanan gizi pada ibu hamil. BBLR dapat menimbulkan dampak kesehatan yang cukup serius di kalangan anakanak. Mulai dari berat badan rendah, kekerdilan, risiko besar terkena penyakit degeneratif hingga kematian pada usia satu tahun. Hal ini semakin menguatkan akan pentingnya memenuhi asupan gizi yang dibutuhkan selama masa kehamilan.

Status gizi yang baik harus ditunjang dengan pemeriksaan diri ibu selama kehamilan. Pemeriksaan kehamilan dianjurkan dilakukan oleh ibu hamil minimal 4 kali selama kehamilan. Pemeriksaan pertama atau kunjungan pertama dilakukan sebelum saat usia kehamilan mencapai 4 bulan atau antara 0-3 bulan (trimester 1). Kunjungan kedua pada usia kehamilan 4-6 bulan (trimester 2). Sedangkan kunjungan ketiga dan empat dilakukan pada usia kehamilan 7-9 bulan (trimester 3). Pemeriksaan kehamilan dapat dilakukan di posyandu, pondok bersalin, puskesmas, rumah sakit, tem- 
pat praktek dokter atau bidan swasta (Depkes RI, 1993). Pemeriksaan kesehatan yang umum dilakukan tenaga kesehatan di masyarakat yaitu pengukuran berat badan dan tinggi badan, tekanan darah (tensi), pemeriksaan tinggi fundus uteri (bagian atas punggung rahim), suntikan imunisasi Tetanus Toksoid (TT), serta pemberian tablet besi (BPS 2004). Pelayanan yang belum memenuhi standar minimal 5T (pengukuran tinggi badan dan berat badan, pengukuran tekanan darah, pemeriksaan tinggi fundus uteri, imunisasi tetanus toksoid dan pemberian tablet besi) belum dapat dikatakan sebagai pelayanan antenatal. Hal ini dilandasi ketetapan pemerintah yang menyatakan bahwa standar pelayanan antenatal minimal yaitu 5T. Hasil survey 5 tahun terakhir menunjukkan bahwa ibu yang menerima jenis pelayanan sesuai standar minimal 5T yaitu baru sekitar 22\% (Kisnawati, 2007).

Thompson (2004) menyatakan bahwa keluhan kehamilan yang paling umum pada masa awal kehamilan (trimester I) adalah morning sick, yaitu mual dan muntah yang terjadi di pagi hari. Kondisi ini umum ditemui pada sebagian besar wanita hamil, tapi bukan berarti tiap wanita hamil akan mengalami hal ini. Kondisi ini biasanya berlangsung sampai usia kehamilan memasuki minggu ke-12 atau bulan ketiga kehamilan. Pemeriksaan kehamilan secara rutin dapat mendeteksi secara dini jika ada kelainan selama masa hamil dan mengambil tindakan antisipasi sesegera mungkin.

\section{$\underline{\text { Tujuan }}$}

Tujuan penelitian ini yaitu 1) mengetahui tingkat pengetahuan gizi dan kesehatan ibu hamil, 2) mengetahui tingkat kepatuhan ibu hamil dalam mengonsumsi tablet besi, 3) mengidentifikasi jenis penyakit yang dialami ibu hamil antara sebelum dan selama kehamilan, 4) mengidentifikasi jenis keluhan pada ibu hamil, 5) mengetahui intensitas pemeriksaan kehamilan dan fasilitas pelayanan kesehatan yang didapat ibu hamil, 6) menganalisis hubungan antara tingkat keluhan yang dialami ibu selama kehamilan dengan intensitas pemeriksaan kehamilan, fasilitas pelayanan kesehatan dan konsumsi tablet besi.

\section{METODE}

\section{Desain, Tempat dan Waktu Penelitian}

Desain penelitian ini adalah cross sectional study. Penelitian ini secara keseluruhan dilakukan pada bulan November 2007 - April
2008. Proses pengumpulan data dilakukan di Kelurahan Kramat Jati (Jakarta Timur) dan Kelurahan Ragunan (Jakarta Selatan) pada bulan November - Desember 2007.

\section{Penarikan Contoh}

Contoh dalam penelitian ini adalah ibu hamil. Penarikan contoh dilakukan dengan metode purposive sampling. Penarikan contoh ibu hamil dilakukan dengan memilih sejumlah ibu hamil di kedua kelurahan yang terdaftar di masing-masing puskesmes wilayah tempat tinggal contoh. Penyaringan data ibu hamil dilakukan setelah pihak puskesmas yang dibantu para kader memberikan data ibu hamil di masingmasing kelurahan. Kelurahan Kramat Jati memiliki jumlah total ibu hamil yang terdata sebanyak 150 orang dan Kelurahan Ragunan memiliki jumlah total ibu hamil yang terdata sebanyak 224 orang. Penyaringan data ibu hamil dilakukan setelah pihak puskesmas yang dibantu oleh para kader memberikan data ibu hamil yang berada di masing-masing kelurahan. Proses penyaringan didasarkan kepada 3 jenis kriteria yang telah ditetapkan, yaitu (1) usia kehamilan antara 12-24 minggu, (2) bukan merupakan kehamilan yang pertama dan (3) bersedia diwawancarai hingga selesai. Pertimbangan penetapan ketiga kriteria tersebut adalah untuk mendapatkan sejumlah contoh ibu hamil dengan pengalaman kehamilan serta akses ke pelayanan kesehatan yang hampir sama. Berdasarkan kriteria-kriteria yang telah ditetapkan tersebut, terdapat 34 contoh dari Kelurahan Kramat Jati dan 31 contoh dari Kelurahan Ragunan yang berhasil memenuhi kriteria.

Jumlah contoh yang telah berhasil memenuhi kriteria masih belum cukup untuk melengkapi jumlah sampel minimal yaitu sebanyak 48. Kriteria kedua pun dibuat agar memenuhi jumlah sampel minimal. Kriteria kedua ini adalah (1) usia kehamilan antara 8-24 minggu, (2) bukan merupakan kehamilan yang pertama dan (3) bersedia diwawancarai hingga selesai. Jumlah contoh yang didapatkan dengan menggunakan kriteria kedua ini yaitu sebanyak 50 contoh dari Kelurahan Kramat Jati dan 50 contoh dari Kelurahan Ragunan.

\section{Jenis dan Cara Pengumpulan Data}

Jenis data yang dikumpulkan pada penelitian ini terdiri dari data primer dan data sekunder. Data primer pada penelitian ini diperoleh melalui proses wawancara secara langsung dengan menggunakan kuesioner. Data primer yang diperoleh meliputi karakteristik ibu hamil, karakteristik keluarga, status gizi, riwa- 
yat kesehatan dan kehamilan, akses terhadap pelayanan kesehatan kehamilan serta pengetahuan gizi dan kesehatan ibu hamil. Data sekunder diperoleh melalui dinas pemerintah kota setempat.

\section{Pengolahan dan Analisis Data}

Data yang diperoleh diolah dengan melalui proses editing, coding, entry dan cleaning dengan menggunakan Microsoft Excel 2003. Serta analisis data dengan menggunakan SPSS 13.00 for Windows. Analisis data menggunakan Rank Spearman Correlation untuk mengetahui hubungan antar variabel. Peubah-peubah utama dalam penelitian ini yaitu tingkat keluhan ibu hamil, cakupan kunjungan ibu hamil (intensitas pemeriksaan kehamilan) dan kelengkapan fasilitas pelayanan antenatal yang diperoleh.

Skoring dan pengkategorian dilakukan dalam proses pengolahan data. Skoring dilakukan terutama pada variabel tingkat keluhan kehamilan, intensitas pemeriksaan kehamilan dan fasilitas pelayanan kesehatan yang didapatkan. Pada variabel tingkat keluhan kehamilan proses skoring terbagi menjadi 2, untuk kategori keluhan ringan diberikan skor 1 dan untuk kategori keluhan berat diberikan skor 2 sehingga didapatkan jumlah total skor tingkat keluhan kehamilan untuk masing-masing responden 27. Pada variabel intensitas pemeriksaan kehamilan total skor adalah 4 . Untuk responden yang memeriksakan kehamilan K1 skor yang diberikan 1 , pemeriksaan $\mathrm{K} 2$ diberikan skor 2, pemeriksaan K3 diberikan skor 3 dan pemeriksaan K4 (secara lengkap) diberikan skor 4. Responden yang sama sekali tidak memeriksakan kehamilannya diberikan skor 0 . Untuk variabel fasilitas pelayanan kesehatan kehamilan, merujuk pada standar pelayanan kesehatan kehamilan yang dikeluarkan oleh Departemen Kesehatan RI. Responden yang mendapatkan salah satu jenis pelayanan kesehatan standar diberikan skor 1 sehingga responden yang mendapatkan pelayanan kesehatan secara lengkap (standar pelayanan 5T) akan mendapatkan skor 5.

\section{HASIL DAN PEMBAHASAN}

\section{Karakteristik Keluarga}

Secara umum responden di Kelurahan Ragunan memiliki karakteristik yang lebih baik bila dibandingkan dengan responden di Kelurahan Kramat Jati. Hal ini dapat dilihat pada Tabel 1 yang menunjukkan persentase yang lebih baik pada hampir seluruh variabel yaitu umur, tingkat pendidikan dan status ekonomi keluarga.

Umur responden berkisar antara 20 hingga 40 tahun. Secara keseluruhan hampir seluruh ibu hamil berada pada kategori umur 20-35 tahun. Pada kategori umur ini, Kelurahan Ragunan memiliki persentase yang lebih besar dibandingkan Kelurahan Kramat Jati (Tabel 1).

Tabel 1 menunjukkan bahwa lebih dari separuh responden secara keseluruhan memiliki tingkat pendidikan sedang. Serupa dengan tingkat pendidikan responden, suami responden juga memiliki tingkat pendidikan sedang. Namun, persentase yang ditunjukkan suami responden lebih besar dalam kategori ini. Sehingga dapat dikatakan bahwa suami responden memiliki tingkat pendidikan lebih baik.

Hampir seluruh responden dalam penelitian ini merupakan sosok ibu rumahtangga atau ibu tidak bekerja. Sedangkan untuk responden yang bekerja, sebagian besar bekerja sebagai pegawai swasta. Kemudian diikuti oleh responden yang berwirausaha. Dan hanya $1.0 \%$ responden yang bekerja sebagai pegawai negeri sipil.

Kisaran besar keluarga responden antara 2-8 orang. Hasil penelitian secara keseluruhan menunjukkan bahwa sebagian besar responden termasuk dalam kategori keluarga kecil. Jumlah responden dengan kategori keluarga kecil di Kelurahan Ragunan lebih banyak (hampir seluruh responden) dibandingkan dengan responden di Kelurahan Kramat Jati.

Hasil penelitian menunjukkan hampir sebagian besar keluarga responden berada pada kategori keluarga tidak miskin. Secara umum berdasarkan tingkat ekonomi keluarga, responden di Kelurahan Ragunan memiliki tingkat ekonomi yang lebih baik dibandingkan dengan tingkat ekonomi keluarga responden di Kelurahan Kramat Jati.

Seluruh responden tersebar pada masing-masing kelompok usia kehamilan. Kisaran usia kehamilan responden yaitu antara 8 - 28 minggu. Lebih dari separuh responden dalam penelitian ini termasuk kedalam kategori pertama (trimester I). Hanya sebagian kecil responden saja berada dalam kategori usia kehamilan trimester III.

Paritas merupakan salah satu faktor risiko kehamilan yang dapat menyebabkan terjadinya perdarahan semasa kehamilan maupun pendarahan pada saat persalinan berlangsung (Depkes RI, 1995 dalam Sutaryanto, 2002). Ha- 
sil penelitian menunjukkan hampir seluruh res ponden memiliki tingkat paritas yang rendah $(\leq$ 5). Hal ini dapat pula diartikan bahwa hampir seluruh responden memiliki tingkat risiko kehamilan yang rendah.

\section{Pengetahuan Gizi dan Kesehatan Ibu Hamil}

Lebih dari separuh responden memiliki tingkat pengetahuan gizi dan kesehatan yang berada pada tingkat sedang. Namun saying- nya, responden dengan tingkat pengetahuan gizi dan kesehatan yang baik memiliki persentase yang lebih kecil dibandingkan dengan responden yang memiliki tingkat pengetahuan gizi dan kesehatan yang buruk. Hasil ini memberkan gambaran bahwa lebih dari separuh ibu hamil hanya memperoleh skor pengetahuan gizi dan kesehatan sebesar 60-80 (Khomsan, 2000). Sebaran responden berdasarkan skor pengetahuan gizi dan kesehatan ibu hamil dapat dilihat selengkapnya pada Tabel 3 .

Tabel 1. Sebaran Responden berdasarkan Umur, Tingkat Pendidikan, Jenis Pekerjaan, Besar Keluarga dan Status Ekonomi Keluarga

\begin{tabular}{|c|c|c|c|c|c|c|}
\hline \multirow{2}{*}{ Variabel } & \multicolumn{2}{|c|}{ Kramat J ati } & \multicolumn{2}{|c|}{ Ragunan } & \multicolumn{2}{|c|}{ TOTAL } \\
\hline & $\mathbf{n}$ & $\%$ & $\mathbf{n}$ & $\%$ & $\mathbf{n}$ & $\%$ \\
\hline \multicolumn{7}{|c|}{ Umur Responden (tahun) } \\
\hline $20-35$ & 43 & 86.00 & 48 & 96.00 & 91 & 91.00 \\
\hline$>35$ & 7 & 14.00 & 2 & 4.00 & 9 & 9.00 \\
\hline TOTAL & 50 & 100.00 & 50 & 100.00 & 100 & 100.00 \\
\hline \multicolumn{7}{|c|}{ Tingkat Pendidikan Responden } \\
\hline Rendah & 10 & 20.00 & 9 & 18.00 & 19 & 19.00 \\
\hline Sedang & 34 & 68.00 & 31 & 62.00 & 65 & 65.00 \\
\hline Tinggi & 6 & 12.00 & 10 & 20.00 & 16 & 16.00 \\
\hline TOTAL & 50 & 100.00 & 50 & 100.00 & 100 & 100.00 \\
\hline \multicolumn{7}{|c|}{ Tingkat Pendidikan Suami } \\
\hline Rendah & 8 & 16.00 & 8 & 16.00 & 16 & 16.00 \\
\hline Sedang & 39 & 78.00 & 36 & 72.00 & 75 & 75.00 \\
\hline Tinggi & 3 & 6.00 & 6 & 12.00 & 9 & 9.00 \\
\hline TOTAL & 50 & 100.00 & 50 & 100.00 & 100 & 100.00 \\
\hline \multicolumn{7}{|c|}{ J enis Pekerjaan Responden } \\
\hline PNS & 1 & 2.00 & 0 & 0.00 & 1 & 1.00 \\
\hline Swasta & 3 & 6.00 & 2 & 4.00 & 5 & 5.00 \\
\hline Wirausaha & 3 & 6.00 & 1 & 2.00 & 4 & 4.00 \\
\hline Ibu rumah tangga & 43 & 86.00 & 47 & 94.00 & 90 & 90.00 \\
\hline TOTAL & 50 & 100.00 & 50 & 100.00 & 100 & 100.00 \\
\hline \multicolumn{7}{|l|}{ Besar Keluarga } \\
\hline$\leq 4$ & 38 & 76.00 & 45 & 90.00 & 83 & 83.00 \\
\hline$>4$ & 12 & 24.00 & 5 & 10.00 & 17 & 17.00 \\
\hline TOTAL & 50 & 100.00 & 50 & 100.00 & 100 & 100.00 \\
\hline \multicolumn{7}{|c|}{ Tingkat Ekonomi Keluarga } \\
\hline Miskin & 15 & 30.00 & 11 & 22.00 & 26 & 26.00 \\
\hline Tidak miskin & 35 & 70.00 & 39 & 78.00 & 74 & 74.00 \\
\hline TOTAL & 50 & 100.00 & 50 & 100.00 & 100 & 100.00 \\
\hline
\end{tabular}

Tabel 2. Sebaran Responden berdasarkan Usia Kehamilan dan Paritas

\begin{tabular}{ccccccc}
\hline \multirow{2}{*}{ Variabel } & \multicolumn{2}{c}{ Kramat J ati } & \multicolumn{2}{c}{ Ragunan } & \multicolumn{2}{c}{ TOTAL } \\
\cline { 2 - 7 } & $\mathbf{n}$ & $\%$ & $\mathbf{n}$ & $\%$ & $\mathbf{n}$ & $\%$ \\
\hline Usia Kehamilan & 26 & 52 & 34 & 68 & 60 & 60 \\
Trimester I & 20 & 40 & 14 & 28 & 34 & 34 \\
Trimester II & 4 & 8 & 2 & 4 & 6 & 6 \\
Trimester III & 50 & 100 & 50 & 100 & 100 & 100 \\
\hline TOTAL & & & & & & \\
\hline Paritas & 46 & 92 & 48 & 96 & 94 & 94 \\
$\leq 5$ & 4 & 8 & 2 & 4 & 6 & 6 \\
$>5$ & 50 & 100 & 50 & 100 & 100 & 100 \\
\hline TOTAL & & & & & &
\end{tabular}


Tabel 3. Sebaran Responden berdasarkan Tingkat Pengetahuan Gizi dan Kesehatan

\begin{tabular}{ccccccc}
\hline $\begin{array}{c}\text { Pengetahuan gizi dan } \\
\text { kesehatan }\end{array}$ & \multicolumn{2}{c}{ Kramat J ati } & \multicolumn{2}{c}{ Ragunan } & \multicolumn{2}{c}{ Total } \\
\cline { 2 - 7 } & $\mathbf{n}$ & $\%$ & $\mathbf{n}$ & $\%$ & $\mathbf{n}$ & $\%$ \\
\hline Buruk & 15 & 30.00 & 11 & 22.00 & 26 & 26.00 \\
Sedang & 24 & 48.00 & 28 & 56.00 & 52 & 52.00 \\
Baik & 11 & 22.00 & 11 & 22.00 & 22 & 22.00 \\
\hline Total & 50 & 100.00 & 50 & 100.00 & 100 & 100.00 \\
\hline
\end{tabular}

Kisaran skor pengetahuan gizi dan kesehatan responden antara 14.3 sampai 100.0 dengan rata-rata skor pengetahuan gizi dan kesehatan ibu hamil yaitu sebesar 69.4. Hal ini menunjukkan tingkat pengetahuan responden sangat beragam. Skor tersebut menunjukkan bahwa terdapat ibu hamil yang mampu menjawab dengan tepat seluruh pertanyaan seputar gizi dan kesehatan kehamilan. Namun, di samping itu terdapat ibu hamil yang hanya mampu menjawab satu pertanyaan dengan tepat.

Hampir seluruh responden mampu menjawab dengan tepat pertanyaan mengenai gejala anemia $(96.0 \%)$ dan makanan sehat bagi ibu hamil (94.0\%). Sebagian besar responden mampu menjawab dengan tepat pertanyaan mengenai risiko apabila bayi lahir prematur (75.0\%), akibat kekurangan zat besi selama kehamilan (81.0\%), jarak kelahiran yang aman (80.0\%), bahan pangan sumber kalsium $(83.0 \%)$ serta bahan pangan sumber protein $(83.0 \%)$. Namun, lebih dari separuh ibu hamil tidak mampu menjawab secara tepat pertanyaan mengenai pertambahan berat badan selama kehamilan $(63.0 \%)$, sumber vitamin C (67.0\%) serta minimal berat badan bayi saat lahir yang sehat $(68.0 \%)$.

Suhardjo (1989) menyatakan bahwa pengetahuan gizi yang baik dapat menghindarkan seseorang dari konsumsi pangan yang salah. Ibu hamil dengan pengetahuan gizi dan kesehatan yang baik dapat memilah bahan pangan yang akan ia konsumsi. Dengan tingkat pengetahuan yang baik ibu hamil dapat mengetahui bahan pangan apa saja yang dapat membahayakan kehamilannya. Hal ini pun dapat berlaku sebaliknya, dengan pengetahuan gizi dan kesehatan yang baik ibu hamil juga dapat memilah bahan pangan apa saja yang dapat menunjang kehamilan sehingga ia dapat menjalani kehamilan dengan baik. Ibu hamil dengan tingkat pengetahuan gizi dan kesehatan yang baik tentunya akan dapat memilah hal-hal yang dapat menunjang kualitas kehamilannya terutama yang terkait dengan konsumsi. Oleh karena itu, pengetahuan akan gizi dan kesehatan yang baik dapat membantu ibu hamil menjalani masa kehamilannya dengan baik pula.
Tingkat Kepatuhan lbu Hamil dalam Mengonsumsi Tablet Tambah Darah

Hasil penelitian menunjukkan hampir sebagian besar ibu hamil yang mengonsumsi tablet tambah darah masih termasuk dalam kategori tidak patuh. Terdapat $74.16 \%$ ibu hamil yang mengonsumsi tablet tambah darah kurang dari $80 \%$. Pada penelitian ini hanya $25.84 \%$ responden saja yang mengonsumsi tablet tambah darah di atas $80 \%$ dan termasuk dalam kategori patuh (Tabel 4). Rata-rata ibu hamil mengonsumsi tablet tambah darah sebanyak 34 tablet dan terdapat ibu hamil yang sama sekali tidak mengonsumsi tablet tambah darah yang diberikan oleh pelayanan kesehatan setempat.

Tabel 4. Sebaran Responden berdasarkan Tingkat Kepatuhan Ibu Hamil dalam Mengonsumsi Tablet Tambah Darah

\begin{tabular}{ccccccc}
\hline Konsumsi & \multicolumn{2}{c}{ Kramat J ati } & \multicolumn{2}{c}{ Ragunan } & \multicolumn{2}{c}{ TOTAL } \\
\cline { 2 - 7 } TTD & $\mathbf{n}$ & $\%$ & $\mathbf{n}$ & $\%$ & $\mathbf{n}$ & $\%$ \\
\hline$<80 \%$ & 37 & 77.08 & 29 & 70.73 & 66 & 74.16 \\
$\geq 80 \%$ & 11 & 22.92 & 12 & 29.27 & 23 & 25.84 \\
\hline TOTAL & 48 & 100.00 & 41 & 100.00 & 89 & 100.00 \\
\hline
\end{tabular}

Pemerintah memprioritaskan suplementasi tablet tambah darah kepada ibu hamil. Suplementasi tablet tambah darah ini dimaksudkan agar ibu hamil terhindar dari anemia. Menurut SKRT (1995) yang diacu dalam Darlina (2003) selain karena mempunyai prevalensi tertinggi (51\%), ibu hamil mendapatkan prioritas dalam program suplementasi tablet tambah darah ini juga karena akibat dari anemia yang tidak hanya membahayakan ibu namun juga janin yang dikandungnya. Selama masa kehamilan tablet tambah darah sebaiknya diminum minimal sebanyak 90 tablet. Namun, akan lebih baik ketika ibu hamil mengonsumsi tablet tambah darah satu tablet setiap hari (Depkes RI, 1993). Konsumsi tablet tambah darah sangat dipengaruhi oleh kesadaran dan kepatuhan ibu hamil. Kesadaran merupakan faktor pendukung bagi ibu hamil untuk patuh mengonsumsi tablet tambah darah secara baik (WHO 1986, dalam Wijianto, 2002). Tingkat kepatuhan yang kurang sangat mungkin dipe- 
ngaruhi oleh rendahnya kesadaran responden dalam mengosumsi tablet tambah darah. Kesadaran untuk mengonsumsi tablet tambah darah ini pun besar kemungkinan mendapat pengaruh melalui tingkat pengetahuan gizi dan kesehatan responden. Secara umum, responden di Kelurahan Ragunan memiliki tingkat kepatuhan mengonsumsi tablet tambah darah yang lebih baik dibandingkan dengan responden di Kelurahan Kramat Jati. Dengan tingkat pengetahuan gizi dan kesehatan yang lebih baik responden di Kelurahan Ragunan memiliki kesadaran yang lebih tinggi dalam mengonsumsi tablet tambah darah tersebut (Suhardjo, 1989).

WHO (1986) dalam Wijianto (2002) juga menyatakan bahwa kepatuhan ibu hamil dalam mengonsumsi tablet tambah darah tidak hanya dipengaruhi oleh kesadaran saja. Terdapat faktor lain yang juga turut mempengaruhi tingkat kepatuhan ibu hamil dalam mengonsumsi tablet tambah darah. Faktor-faktor tersebut antara lain adalah bentuk tablet, warna, rasa dan efek samping. Dari sekian banyak faktor tersebut salah satu faktor yang berpengaruh besar dalam tingkat kepatuhan ibu hamil mengonsumsi tablet tambah darah adalah efek samping. Efek samping dari tablet tambah darah antara lain mengakibatkan nyeri lambung, mual, muntah, konstipasi dan diare. Adanya efek samping dari tablet tambah darah ini diduga menyebabkan ibu hamil menjadi enggan dalam mengonsumsi tablet tambah darah yang diberikan oleh pelayanan kesehatan setempat sehingga memperbesar prevalensi ketidakpatuhan ibu hamil dalam mengonsumsi tablet besi.
Lenis Penyakit yang Dialami lbu Sebelum Hamil dan Selama Hamil

Terdapat perbedaan jenis penyakit yang sering muncul pada saat 6 bulan sebelum hamil dan selama masa kehamilan. Secara umum, mulai dari persentase terbesar, jenis penyakit yang sering muncul pada saat 6 bulan sebelum hamil adalah influenza, batuk, anemia, maag, hipertensi, jantung, asma dan sinus. Sedangkan jenis penyakit yang sering muncul selama masa kehamilan, mulai dari persentase terbesar adalah anemia, batuk, influenza, maag, typus, asma, hiperemesis, sinus, muntaber dan radang tenggorokan. Sebaran responden berdasarkan jenis penyakit yang diderita disajikan secara lengkap pada Tabel 5.

Pada Tabel 5 terlihat bahwa secara keseluruhan dari total responden di kedua kelurahan, anemia memiliki persentase yang meningkat pada saat 6 bulan sebelum hamil dan selama kehamilan. Persentase anemia pada saat 6 bulan sebelum hamil sebesar yaitu 15.6\%. Sedangkan persentase anemia selama kehamilan meningkat hingga $28.7 \%$. Meningkatnya prevalensi anemia selama masa kehamilan menunjukkan pentingnya mengonsumsi tablet tambah darah sesuai yang anjuran. Anemia yang terjadi saat kehamilan dapat ditanggulangi dengan mengonsumsi tablet besi secara teratur 1 tablet setiap hari atau minimal sebanyak 90 tablet selama kehamilan (BPS, 2004). Peningkatan persentase jenis penyakit selama kehamilan juga terjadi pada penyakit typus, hiperemesis, muntaber dan radang tenggorokan.

Tabel 5. Sebaran Responden berdasarkan Jenis Penyakit yang Diderita Selama Enam Bulan Sebelum Hamil dan Selama Kehamilan

\begin{tabular}{|c|c|c|c|c|c|c|c|c|c|c|c|c|}
\hline \multirow{3}{*}{ Jenis Penyakit } & \multicolumn{6}{|c|}{6 bulan sebelum hamil } & \multicolumn{6}{|c|}{ Selama kehamilan } \\
\hline & \multicolumn{2}{|c|}{ Kramat J ati } & \multicolumn{2}{|c|}{ Ragunan } & \multicolumn{2}{|c|}{ TOTAL } & \multicolumn{2}{|c|}{ Kramat J ati } & \multicolumn{2}{|c|}{ Ragunan } & \multicolumn{2}{|c|}{ TOTAL } \\
\hline & $\mathbf{n}$ & $\%$ & $\mathbf{n}$ & $\%$ & $\mathbf{n}$ & $\%$ & $\mathbf{n}$ & $\%$ & $\mathbf{n}$ & $\%$ & $\mathbf{n}$ & $\%$ \\
\hline Anemia & 9 & 18.37 & 6 & 12.77 & 15 & 15.63 & 17 & 37.78 & 10 & 20.41 & 27 & 28.72 \\
\hline Batuk & 16 & 32.65 & 14 & 29.79 & 30 & 31.25 & 11 & 24.44 & 16 & 32.65 & 27 & 28.72 \\
\hline Influenza & 15 & 30.61 & 16 & 34.04 & 31 & 32.29 & 8 & 17.78 & 15 & 30.61 & 23 & 24.47 \\
\hline Hipertensi & 1 & 2.04 & 2 & 4.26 & 3 & 3.13 & 0 & 0.00 & 0 & 0.00 & 0 & 0.00 \\
\hline Jantung & 1 & 2.04 & 1 & 2.13 & 2 & 2.08 & 0 & 0.00 & 0 & 0.00 & 0 & 0.00 \\
\hline Diabetes & 0 & 0.00 & 0 & 0.00 & 0 & 0.00 & 0 & 0.00 & 0 & 0.00 & 0 & 0.00 \\
\hline Typus & 0 & 0.00 & 0 & 0.00 & 0 & 0.00 & 1 & 2.22 & 0 & 0.00 & 1 & 1.06 \\
\hline Asma & 2 & 4.08 & 0 & 0.00 & 2 & 2.08 & 1 & 2.22 & 0 & 0.00 & 1 & 1.06 \\
\hline Maag & 4 & 8.16 & 8 & 17.02 & 12 & 12.50 & 4 & 8.89 & 7 & 14.29 & 11 & 11.70 \\
\hline Hiperemesis & 0 & 0.00 & 0 & 0.00 & 0 & 0.00 & 1 & 2.22 & 0 & 0.00 & 1 & 1.06 \\
\hline Sinus & 1 & 2.04 & 0 & 0.00 & 1 & 1.04 & 1 & 2.22 & 0 & 0.00 & 1 & 1.06 \\
\hline Muntaber & 0 & 0.00 & 0 & 0.00 & 0 & 0.00 & 1 & 2.22 & 0 & 0.00 & 1 & 1.06 \\
\hline Radang tenggorokan & 0 & 0.00 & 0 & 0.00 & 0 & 0.00 & 0 & 0.00 & 1 & 2.04 & 1 & 1.06 \\
\hline TOTAL & 49 & 100.00 & 47 & 100.00 & 96 & 100.00 & 45 & 100.00 & 49 & 100.00 & 94 & 100.00 \\
\hline
\end{tabular}


Thompson (2004) menyatakan bahwa terdapat 4 jenis penyakit yang sering muncul terkait dengan kehamilan. Penyakit-penyakit tersebut adalah anemia, hipertensi, diabetes dan ambeien. Keempat penyakit tersebut merupakan penyakit yang umum muncul selama masa-masa kehamilan. Hal ini memperkuat hasil penelitian yang menunjukkan terdapat peningkatan persentase anemia pada ibu hamil. Berbeda halnya dengan anemia, penyakitpenyakit lain (hipertensi, diabetes dan ambeien) tidak menunjukkan adanya peningkatan persentase pada saat selama hamil.

Berdasarkan kategori penyakit, lebih dari separuh responden berada dalam kategori skor morbiditas (skor penyakit) yang dianggap ringan baik itu pada saat 6 bulan sebelum hamil maupun pada saat hamil. Skor morbiditas responden yang hampir sebagian besar responden dinyatakan ringan, menunjukkan bahwa hampir sebagian besar responden memiliki risiko kehamilan yang tidak diakibatkan oleh morbiditas.

\section{Tingkat Keluhan Ibu selama Kehamilan}

Thompson (2004) menyatakan bahwa keluhan kehamilan yang paling umum dijumpai pada masa-masa awal kehamilan (trimester I) adalah morning sick, yaitu mual dan muntah yang terjadi di pagi hari. Kondisi ini umum ditemui pada sebagian besar wanita hamil, namun dapat juga tidak dialami oleh wanita hamil lainnya. Kondisi ini biasanya akan berlangsung hingga usia kehamilan memasuki minggu ke-12 atau bulan ketiga kehamilan. Gangguan ini diperkirakan terjadi karena peningkatan hormon HCG (Human Chorionic Gonadotropin) selama 3 bulan pertama kehamilan. Penyebab lain ialah stress, bau yang menyengat, pengaruh meminum tablet zat besi pada awal kehamilan, sulit menelan serta melihat atau mencium makanan yang tidak disukai.

Senada dengan pernyataan Thompson (2004) bahwa keluhan kehamilan yang paling umum ditemui pada masa-masa awal kehamilan (trimester I) adalah morning sick. Secara keseluruhan responden di Kelurahan Kramat Jati dan Ragunan mengungkapkan hal yang sama. Sebanyak $80.00 \%$ responden mengalami jenis keluhan mual. Namun, keluhan mual pada masa kehamilan tidak selalu diiringi dengan muntah. Berdasarkan Tabel 7, ibu hamil dengan keluhan muntah memiliki persentase lebih kecil dibandingkan ibu hamil dengan keluhan mual saja. Persentase terbesar kedua untuk

Tabel 6. Sebaran Responden berdasarkan Skoring Penyakit

\begin{tabular}{|c|c|c|c|c|c|c|c|c|c|c|c|c|}
\hline \multirow{3}{*}{ Kategori } & \multicolumn{6}{|c|}{6 bulan sebelum hamil } & \multicolumn{6}{|c|}{ Selama kehamilan } \\
\hline & \multicolumn{2}{|c|}{ Kramat jati } & \multicolumn{2}{|c|}{ Ragunan } & \multicolumn{2}{|c|}{ TOTAL } & \multicolumn{2}{|c|}{ Kramat jati } & \multicolumn{2}{|c|}{ Ragunan } & \multicolumn{2}{|c|}{ TOTAL } \\
\hline & $\mathbf{n}$ & $\%$ & $\mathbf{n}$ & $\%$ & $\mathbf{n}$ & $\%$ & $\mathbf{n}$ & $\%$ & $\mathbf{n}$ & $\%$ & $\mathbf{n}$ & $\%$ \\
\hline Ringan & 32 & 64.00 & 37 & 74.00 & 69 & 69.00 & 35 & 70.00 & 36 & 72.00 & 71 & 71.00 \\
\hline Sedang & 13 & 26.00 & 7 & 14.00 & 20 & 20.00 & 13 & 26.00 & 8 & 16.00 & 21 & 21.00 \\
\hline Berat & 5 & 10.00 & 6 & 12.00 & 11 & 11.00 & 2 & 4.00 & 6 & 12.00 & 8 & 8.00 \\
\hline TOTAL & 50 & 100.00 & 50 & 100.00 & 100 & 100.00 & 50 & 100.00 & 50 & 100.00 & 100 & 100.00 \\
\hline
\end{tabular}

Tabel 7. Sebaran Responden berdasarkan Jenis Keluhan yang Dialami Selama Kehamilan

\begin{tabular}{lcccccc} 
& \multicolumn{2}{c}{ Kramat J ati } & \multicolumn{2}{c}{ Ragunan } & \multicolumn{2}{c}{ TOTAL } \\
\cline { 2 - 6 } & $\mathbf{n}$ & $\%$ & $\mathbf{n}$ & $\%$ & $\mathbf{n}$ & $\%$ \\
\hline Mual & 41 & 82.00 & 39 & 78.00 & 80 & 80.00 \\
Muntah & 32 & 64.00 & 28 & 56.00 & 60 & 60.00 \\
Pusing/berkunang & 38 & 76.00 & 30 & 60.00 & 68 & 68.00 \\
Lemah/lesu & 34 & 68.00 & 25 & 50.00 & 59 & 59.00 \\
Pucat & 26 & 52.00 & 21 & 42.00 & 47 & 47.00 \\
Oedema & 3 & 6.00 & 3 & 6.00 & 6 & 12.00 \\
Nafsu makan menurun & 23 & 46.00 & 25 & 50.00 & 48 & 48.00 \\
Merasa kurus & 14 & 28.00 & 13 & 26.00 & 27 & 27.00 \\
Sulit BAB & 8 & 16.00 & 4 & 8.00 & 12 & 12.00 \\
Sering BAK & 36 & 72.00 & 36 & 72.00 & 72 & 72.00 \\
Sakit pinggang & 24 & 48.00 & 20 & 40.00 & 44 & 44.00 \\
Nyeri payudara & 16 & 32.00 & 13 & 26.00 & 29 & 29.00 \\
Sakit pundak & 1 & 2.00 & 0 & 0.00 & 1 & 1.00 \\
Nyeri perut & 1 & 2.00 & 1 & 2.00 & 2 & 2.00 \\
Gatal-gatal & 3 & 6.00 & 3 & 6.00 & 6 & 6.00 \\
Ngidam & 0 & 0.00 & 2 & 4.00 & 2 & 2.00 \\
Alergi & 0 & 0.00 & 1 & 2.00 & 1 & 1.00 \\
Jantung berdebar & 0 & 0.00 & 1 & 2.00 & 1 & 1.00 \\
Pegal-pegal & 0 & 0.00 & 2 & 4.00 & 2 & 2.00 \\
\hline
\end{tabular}


jenis keluhan selama kehamilan yaitu adalah sering BAK (Buang Air Kecil). Responden di kedua kelurahan menyatakan ini sebagai keluhan yang paling umum dijumpai selama masa kehamilan. Persentase terbesar ketiga yaitu jenis keluhan pusing/berkunang. Jenis keluhan ini kemungkinan besar terkait dengan prevalensi anemia yang meningkat selama masa kehamilan. Keluhan ini dapat ditanggulangi dengan mengonsumsi tablet besi satu kali sehari atau minimal sebanyak 90 tablet selama kehamilan (BPS, 2004). Jenis keluhan responden secara lengkap disajikan melalui Tabel 7.

Jenis keluhan yang telah terindentifikasi kemudian diskor. Skor dilakukan berdasarkan kategori jenis keluhan ringan dan berat. Jenis keluhan yang termasuk kedalam kategori berat adalah jenis keluhan yang terkait dengan jenis penyakit tertentu. Skor jenis keluhan responden disajikan melalui Tabel 8.

Tabel 8. Sebaran Responden berdasarkan Kategori Tingkat Keluhan

\begin{tabular}{cccccccc}
\hline \multirow{2}{*}{$\begin{array}{c}\text { Kategori Tingkat } \\
\text { Keluhan }\end{array}$} & \multicolumn{1}{c}{ Kramat J ati } & \multicolumn{2}{c}{ Ragunan } & \multicolumn{2}{c}{ TOTAL } \\
\cline { 2 - 7 } & $\mathbf{n}$ & $\%$ & $\mathbf{n}$ & $\%$ & $\mathbf{n}$ & $\%$ \\
\hline Ringan & 12 & 24.00 & 19 & 38.00 & 31 & 31.00 \\
Berat & 38 & 76.00 & 31 & 62.00 & 69 & 69.00 \\
\hline TOTAL & 50 & 100.00 & 50 & 100.00 & 100 & 100.00 \\
\hline
\end{tabular}

Secara umum, lebih dari separuh responden termasuk kedalam kategori tingkat keluhan berat (Tabel 8). Hal ini berarti mayoritas responden membutuhkan penanganan khusus dalam mengatasi keluhan-keluhan yang muncul selama kehamilan. Jenis keluhan yang dijumpai pada lebih dari separuh responden adalah mual, sering BAK, pusing/berkunang, muntah serta lemah/lesu.

\section{Intensitas pemeriksaan kehamilan}

Pemeriksaan kehamilan dianjurkan dilakukan oleh ibu hamil minimal sebanyak 4 kali selama kehamilan. Pemeriksaan pertama atau kunjungan pertama dilakukan sebelum usia kehamilan mencapai empat bulan atau antara 03 bulan (trimester 1 ). Kunjungan kedua pada usia kehamilan 4-6 bulan (trimester 2). Sedangkan untuk kunjungan ketiga dan keempat dilakukan pada usia kehamilan 7-9 bulan (trimester 3). Pemeriksaan kehamilan dapat dilakukan di posyandu, pondok bersalin, puskesmas, rumah sakit, tempat praktek dokter atau bidan swasta (Depkes RI, 1993).

Lebih dari separuh responden di kedua kelurahan tidak lengkap dalam memeriksakan kehamilannya. Sebanyak $60.00 \%$ responden ti- dak memeriksakan kehamilan sesuai anjuran pemerintah yaitu minimal 4 kali selama kehamilan. Namun, dalam hal ini responden di Kelurahan Ragunan memiliki intensitas pemeriksaan kehamilan yang lebih baik dibandingkan dengan responden di Kelurahan Kramat Jati. Pernyataan ini sesuai dengan persentase intensitas pemeriksaan kehamilan yang tidak lengkap dimana responden Kelurahan Ragunan memiliki intensitas yang lebih kecil dibandingkan dengan responden di Kelurahan Kramat Jati (Tabel 9).

Tabel 9. Sebaran Responden berdasarkan Intensitas Pemeriksaan Kehamilan

\begin{tabular}{ccccccc}
\hline $\begin{array}{c}\text { Intensitas } \\
\text { Pemeriksaan } \\
\text { Kehamilan }\end{array}$ & \multicolumn{2}{c}{ Kramat J ati } & \multicolumn{2}{c}{ Ragunan } & \multicolumn{2}{c}{ TOTAL } \\
\cline { 2 - 7 } & $\mathbf{n}$ & $\mathbf{n}$ & $\%$ & $\mathbf{n}$ & $\%$ \\
\hline Tidak lengkap & 32 & 64.00 & 28 & 56.00 & 60 & 60.00 \\
Lengkap & 18 & 36.00 & 22 & 44.00 & 40 & 40.00 \\
\hline TOTAL & 50 & 100.00 & 50 & 100.00 & 100 & 100.00 \\
\hline
\end{tabular}

Rachmawati (2004) menyatakan terdapat faktor-faktor yang mempengaruhi pertimbangan ibu hamil dalam memilih tempat periksa kehamilan antara lain adalah biaya, jarak dan faktor kepercayaan. Jarak antara tempat tinggal dengan pelayanan kesehatan menjadi salah satu faktor yang menentukan dalam intensitas pemeriksaan ibu hamil. Rendahnya intensitas pemeriksaan kehamilan responden diduga disebabkan oleh jarak tempuh yang jauh serta faktor kepercayaan terhadap tenaga kesehatan pemerintah.

\section{Fasilitas pelayanan kesehatan kehamilan}

Pemeriksaan kesehatan yang umum dilakukan oleh tenaga kesehatan di kalangan masyarakat adalah pengukuran berat badan dan tinggi badan, pengukuran tekanan darah (tensi), pemeriksaan tinggi fundus uteri (bagian atas punggung rahim), suntikan imunisasi Tetanus Toksoid (TT), serta pemberian tablet besi (BPS, 2004). Komponen fasilitas pemeriksaan ibu hamil ini kerap kali disebut sebagai 5T. Fasilitas pemeriksaan kesehatan inilah yang dijadikan standar dalam berbagai pelayanan kesehatan ibu hamil.

Kelengkapan fasilitas pelayanan kesehatan kehamilan tidak begitu saja dijamin oleh akses ke ibukota Negara. Hal ini tercermin melalui persentase kelengkapan fasilitas pelayanan kesehatan kehamilan yang didapat responden di Kelurahan Kramat Jati dan Kelurahan Ragunan. Sebagian besar responden di kedua kelurahan ini tidak mendapatkan fasilitas pelayanan kesehatan kehamilan secara lengkap. 
Hal yang lebih menyedihkan adalah hanya sebagian kecil responden saja yang mendapatkan fasilitas pelayanan kesehatan kehamilan secara lengkap (Tabel 10).

Tabel 10. Sebaran Responden berdasarkan Kelengkapan Fasilitas Pelayanan Kesehatan Kehamilan

\begin{tabular}{|c|c|c|c|c|c|c|}
\hline \multirow{2}{*}{$\begin{array}{c}\text { Fasilitas } \\
\text { Pelayanan } \\
\text { Kesehatan } \\
\text { Kehamilan } \\
\end{array}$} & \multicolumn{2}{|c|}{ Kramat J ati } & \multicolumn{2}{|c|}{ Ragunan } & \multicolumn{2}{|c|}{ TOTAL } \\
\hline & $n$ & $\%$ & $n$ & $\%$ & $\mathbf{n}$ & $\%$ \\
\hline Tidak lengkap & 43 & 86.00 & 46 & 92.00 & 89 & 89.00 \\
\hline Lengkap & 7 & 14.00 & 4 & 8.00 & 11 & 11.00 \\
\hline TOTAL & 50 & 100.00 & 50 & 100.00 & 100 & 100.00 \\
\hline
\end{tabular}

\section{Analisis Hubungan}

Responden dengan intensitas pemeriksaan kehamilan yang lebih lengkap cenderung memiliki tingkat kepatuhan yang lebih tinggi dalam mengonsumsi tablet besi. Hasil uji analisis menunjukkan hubungan positif yang sangat signifikan antara tingkat kepatuhan ibu hamil dalam mengonsumsi tablet besi dengan intensitas pemeriksaan kehamilan ( $p$ value $=$ 0.001 dan $r=0.322^{* *}$ ).

Ibu hamil yang memeriksakan kehamilannya sesuai anjuran memiliki tingkat kepatuhan dalam mengonsumsi tablet besi lebih tinggi dibandingkan ibu hamil yang tidak memeriksakan kehamilannya sesuai anjuran. Hal ini diduga disebabkan ibu hamil dengan tingkat kepatuhan yang tinggi memiliki pengetahuan gizi dan kesehatan yang lebih baik karena ibu hamil ini rutin memeriksakan kehamilannya. Dengan pemeriksaan kehamilan yang rutin (sesuai anjuran), maka ibu hamil akan lebih sering berinteraksi dengan tenaga kesehatan yang memungkinkan pertukaran informasi terjadi lebih sering. Dugaan ini diperkuat dengan hasil penelitian Indahwati (2000) yang mengungkap bahwa terdapat kecenderungan pada ibu hamil dengan konsumsi tablet besi yang baik sebagian besar mempunyai pengetahuan gizi yang baik.

Responden dengan intensitas pemeriksaan kehamilan yang lebih sering cenderung mendapatkan fasilitas pelayanan kesehatan lebih lengkap. Hasil uji analisis menunjukkan intensitas pemeriksaan kehamilan memiliki hubungan positif yang sangat signifikan dengan fasilitas pelayanan kesehatan kehamilan ( $p$ value $=0.002$ dan $r=0.300^{* *}$ ). Hasil penelitian ini diperkuat dengan pernyataan Hartoyo et al, (2003) yang menjelaskan kaitan antara cakupan kunjungan ibu hamil ke pelayanan kese- hatan dengan pelayanan antenatal yang diperoleh.

Lebih dari separuh responden (69.0\%) memiliki tingkat keluhan kehamilan yang tergolong berat. Responden dengan kategori ini memiliki keluhan kehamilan dengan jumlah lebih dari 13.

Intensitas pemeriksaan kehamilan yang dilakukan responden juga tidak berada pada kategori yang memuaskan. Lebih dari separuh responden tidak memeriksakan kehamilan sesuai anjuran (kurang dari 4 kali). Hasil uji analisis menyatakan bahwa tidak terdapat hubungan yang signifikan antara tingkat keluhan ibu hamil dengan intensitas pemeriksaan kehamilan $(p$ value $=0.053$ dan $r=0.194)$.

Fasilitas pelayanan kesehatan kehamilan minimal yang diperoleh ibu hamil adalah pengukuran berat dan tinggi badan, pengukuran tekanan darah, pemeriksaan tinggi fundus uteri, suntikan imunisasi Tetanus Toksoid (TT) dan pemberian tablet besi (BPS, 2004). Hampir seluruh responden dalam penelitian mengaku tidak mendapatkan fasilitas pelayanan kesehatan kehamilan tersebut secara lengkap.

Hasil uji analisis menunjukkan bahwa tidak terdapat hubungan yang signifikan antara tingkat keluhan ibu hamil dengan kelengkapan fasilitas pelayanan kesehatan kehamilan ( $p$ value $=0.780$ dan $r=0.028$ ). Tidak terdapatnya hubungan ini diduga disebabkan karena fasilitas pelayanan kesehatan kehamilan yang tersedia tidak begitu berpengaruh terhadap keluhan kehamilan pada umumnya.

\section{KESIMPULAN}

Lebih dari separuh responden (52.0\%) memiliki tingkat pengetahuan gizi dan kesehatan sedang. Rata-rata skor pengetahuan gizi

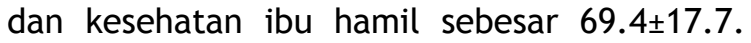
Hampir sebagian besar responden (74.2\%) dinyatakan tidak patuh dalam mengonsumsi tablet besi yang diberikan. Rata-rata konsumsi tablet besi oleh responden yaitu sebanyak 34 tablet.

Jenis penyakit yang diderita responden selama 6 bulan sebelum hamil dengan urutan persentase mulai dari yang terbesar adalah influenza, batuk, anemia, maag, hipertensi, jantung, asma dan sinus. Sedangkan jenis penyakit yang diderita selama kehamilan adalah anemia, batuk, influenza, maag, typus, asma, hiperemesis, sinus, muntaber dan radang tenggorokan. Hampir sebagian besar responden 
(71.0\%) memiliki jumlah skor morbiditas yang tergolong ringan.

Jenis keluhan yang dialami responden bervariasi. Berikut adalah jenis keluhan ibu hamil dengan urutan persentase terbesar hingga terkecil mual, sering BAK (buang air kecil), pusing/berkunang, muntah, lemah/lesu, nafsu makan menurun, merasa gemuk, pucat, sakit pinggang, nafsu makan meningkat, nyeri payudara, merasa kurus, sulit BAB (buang air besar) oedema, gatal-gatal, nyeri perut, ngidam, pegal-pegal, sakit pundak, alergi dan jantung berdebar. Lebih dari separuh responden $(69.0 \%)$ tergolong dalam kategori ibu hamil dengan tingkat keluhan berat.

Lebih dari separuh responden $(60.0 \%)$ tidak memeriksakan kehamilannya sesuai anjuran (minimal 4 kali selama kehamilan) dan sebagian besar responden (89.0\%) tidak mendapatkan fasilitas pelayanan kesehatan secara lengkap dengan standar 5T (pengukuran tinggi badan dan berat badan, pengukuran tekanan darah, pengukuran tinggi fundus uteri, pemberian tablet besi dan imunisasi tetanustoksoid).

Hasil uji analisis menunjukkan hubungan yang sangat signifikan antara tingkat kepatuhan ibu hamil dalam mengonsumsi tablet besi dengan intensitas pemeriksaan kehamilan.

Hasil uji analisis menunjukkan hubungan yang sangat signifikan antara intensitas pemeriksaan kehamilan dengan fasilitas pelayanan kesehatan yang didapatkan responden. Hubungan yang tidak signifikan ditunjukkan oleh tingkat keluhan dengan intensitas pemeriksaan kehamilan dan tingkat keluhan dengan fasilitas pelayanan kesehatan yang didapat.

\section{UCAPAN TERIMA KASIH}

Terima kasih kepada Dr. Sri Anna Marliyati dan Ir. C.M. Dwiriani, MSc atas kesempatan penelitian yang diberikan.

\section{DAFTAR PUSTAKA}

Badan Pusat Statistik. 2004. Statistika Kesehatan. BPS, Jakarta.

Darlina. 2003. Faktor-Faktor yang Berhubungan dengan Kejadian Anemia Gizi pada Ibu
Hamil di Kota Bogor Propinsi Jawa Barat. Skripsi sarjana Jurusan Gizi Mayarakat dan Sumberdaya Keluarga, Fakultas Pertanian, IPB, Bogor.

Departemen Kesehatan Republik Indonesia. 1993. Buku Pedoman Pelacakan Neonatal Risiko Tinggi: Modul tetanus neonatorium dan berat bayi lahir rendah. Depkes RI, Jakarta

2003. Gizi dalam Angka. Depkes RI, Jakarta.

Hartoyo et al. 2003. Studi Evaluasi Health and Nutrition Sector Development Program (HNSDP). Departemen Gizi Masyarakat, Fakultas Pertanian, IPB, Bogor.

Khomsan A. 2000. Teknik Pengukuran Pengetahuan Gizi. Diktat Departemen Gizi Masyarakat dan Sumberdaya Keluarga, Fakultas Pertanian, IPB, Bogor.

Kisnawati D. 2007. Partisipasi Ibu Hamil terhadap Kunjungan Antenatal Care di Puskesmas Pembantu Lung Bata Kota Banda Aceh Tahun 2007. www.contohskripsi tesis.com. [30 Juni 2008].

Rachmawati E. 2004. Kualitas Pelayanan Kesehatan Ibu Hamil dan Bersalin: Antara harapan hidup dan kenyataan kematian. Eja Insani, Bandung

Soehardi S. 2004. Memelihara Kesehatan Jasmani Melalui Makanan. Penerbit ITB, Bandung.

Suhardjo. 1989. Sosio Budaya Gizi. Departemen Pendidikan dan Kebudayaan, Direktorat Jenderal Pendidikan Tinggi, Pusat Antar Universitas Pangan dan Gizi IPB, Bogor.

Thompson J. 2004. Kehamilan dari Pembuahan Hingga Kelahiran. Dian rakyat, Jakarta.

Wijianto. 2002. Dampak Suplementasi Tablet Tambah Darah (TTD) dan Faktor-Faktor yang Berpengaruh Terhadap Anemia Gizi Ibu Hamil di Kab. Banggai Propinsi Sulawesi Tengah. Skripsi sarjana Jurusan Gizi Masyarakat dan Sumberdaya Keluarga Fakultas Pertanian, IPB, Bogor. 